\title{
Electronic Portfolios as Capstone Experiences in a Graduate Program in Organizational Leadership
}

\author{
Brent J. Goertzen, Ph.D. \\ Professor \\ Department of Leadership Studies \\ Fort Hays State University \\ Hays, KS \\ Jeni McRay, Ph.D. \\ Assistant Professor \\ Department of Leadership Studies \\ Fort Hays State University \\ Hays, KS \\ Kaley Klaus \\ Lecturer and Director of VALUE Program \\ Department of Leadership Studies \\ Fort Hays State University \\ Hays, KS
}

\begin{abstract}
Assessment of student learning in graduate education often takes the form of a summative measure by way of written comprehensive exams. However, written examinations, while suitable for evaluating cognitive knowledge, may not fully capture students' abilities to transfer and apply leadership related knowledge and skills into real-world practice. This application brief describes a new form of comprehensive exam in the form of an e-portfolio process, and how an institution has turned a common assessment management tool into an instrument for learning. This brief offers the perspectives of two professors who developed and assessed the student projects, as well as a graduate student who has completed the process. Recommendations for future use to enhance the quality of the experience are also discussed.

\section{Introduction}

The field of leadership studies is often conceived as an interdisciplinary endeavor (Riggio, Ciulla, \& Sorenson, 2003). Leadership is both a topic of study and a set of knowledge and skills to be applied in leading others and organizations. Therefore, it is essential for participants of leadership programs to develop not only an understanding of leadership concepts but that they are also afforded "structured opportunities to apply theories and concepts learned in the classroom” (Riggio, et. al., 2003, p. 229).
\end{abstract}


How do leadership educators facilitate such opportunities for our students? Teaching and learning practices common to the discipline, described by Shulman (2005) as signature pedagogies, can offer some insight into answering this question. Signature pedagogies are types of instructional activities that come to mind when contemplating the preparation of individuals of a particular profession. Extending prior research by Allen and Hartman (2008), Jenkins (2012) examined 24 'signature pedagogies' common among undergraduate leadership programs. Jenkins (2012) provided a thorough overview of common instructional strategies including case studies, class discussion, group projects/presentations, reflective journals and simulations, among many others. Still, perhaps due to the multidisciplinary nature of the field of leadership studies, leadership educators often strive to push the boundaries of commonly accepted pedagogical practices to adopt innovative approaches for teaching and learning, and such is the subject of the current application brief.

This application brief explains how one institution implemented an electronic portfolio which serves as the comprehensive examination for students enrolled in an organizational leadership graduate program. This brief first describes a review of the literature on portfolios (and more recently, electronic portfolios or e-portfolios) in higher education. Second, it describes the specific assignment in the context of the program's capstone experience. Finally, it includes both faculty and student reflections, along with proposed recommendations for future use and research.

\section{Review of Related Literature}

Portfolios are a key feature in higher education institutions in a wide range of academic fields. Early conceptions of today's portfolios are traced back to the mid-1980s with the work of Elbow and Belanoff (1986), who experimented with portfolios as an alternative to comprehensive exams. With the advent of the internet and other technologies, e-portfolios have often replaced more traditional, paper-based portfolios. An e-portfolio "is a digitized collection of artifacts, including demonstrations, resources, and accomplishments that represent an individual, group, community, organization or institution" (Lorenzo \& Ittelson, 2005, p. 2).

Different constituency groups may realize tremendous benefits from e-portfolios. For instance, students benefit by engaging in critical self-reflection of their learning on academic and professional goals, as well as being able to present accomplishments to current and/or potential employers (Reese \& Levy, 2009). Faculty benefit by gaining a more comprehensive understanding of what students are learning in their courses, improving student advising, and enhancing the ability to write more specific letters of recommendation for students. Departments and institutions benefit by gaining critical information that supports both internal assessment and external departmental review, as well as providing the ability to maintain connections and build relationships with alumni (Reese \& Levy, 2009).

\section{Electronic Portfolios for Learning and Assessment}

At the program level, e-portfolios for learning and assessment emerged from academic fields such as writing and teacher preparation programs. More recently, universities have adopted the institution-wide practice of e-portfolios for student learning and assessment (Lorenzo \& 
Ittelson, 2005). E-portfolios as both student learning and assessment tools have been widely adopted across the globe and are well documented in regions and countries such as Europe and the United Kingdom (European Institute for E-Learning, 2009), New Zealand (Bhattacharya \& Hartnett, 2007), China (Chau, 2007), Canada (Abrami \& Barrett, 2005), and the United States (Lorenzo \& Ittelson, 2005).

Barrett (2004) warns against confusing 'e-portfolios for learning' with e-portfolios as 'assessment management systems,' as assessment management systems are largely intended for formative and summative assessment purposes. Within this paradigm, the locus of control for the electronic portfolio is institution-centered, whereby learning outcomes and artifacts to be included are prescribed by the institution. Essentially, the e-portfolio becomes a receptacle for examples of student work.

In contrast, 'e-portfolios for learning' are student-centered, whereby the learner constructs meaning. As such, the learner selects items that reflect learning from the student's perspective (Barrett, 2007). Perhaps the most important benefit of 'e-portfolios for learning' is that they require students to engage in reflective practice, which in turn promotes self-reflection and other meta-cognitive abilities (Abrami \& Barrett, 2005). Reflective practice is generally characterized as ways in which individuals "critically interrogate" their ability to engage in the leadership process and consider how they might improve or refine their practice (Lyons, 1998).

\section{Reflective Practice}

McCall (2004) asserted that the primary source of learning leadership is through experience. While experiences may be a necessary condition for leader development, it alone is not always a sufficient condition. John Dewey urged learners to "reflect in order that we may get hold of the full adequate significance of what happens" (Dewey, 1933, p. 119). Today, reflection is a key feature of contemporary learning theories.

Experiential Learning Theory (ELT) serves as a strong foundation for leadership education (Guthrie \& Jones, 2012). Kolb's (1984) ELT asserted that learning occurs in a fourphased cycle: 1) concrete experience, 2) abstract conceptualization, 3) reflective observation, and 4) active experimentation. Reflective observation occurs through careful observations prior to making judgments and viewing issues from multiple perspectives. Kolb asserted that learning is best conceived as a process as compared to an outcome; reflective observation is therefore an essential component of the learning cycle.

Reflection is "the process of stepping back from an experience to ponder, carefully and persistently, its meaning to the self through the development of inferences; learning is the creation of meaning from past or current events that serves as a guide for future behavior" (Daudlin, 1996, p. 39). In essence, reflection is the process of critically thinking aboutour behaviors, attitudes, beliefs and values (Roberts, 2008) and is used as a way to integrate theory to practice, as well as stimulate insight and self-discovery (Mezirow, 1998). Reflective practice can enhance students' self-awareness (Day, Fleenor, Atwater, Sturm, \& McKee, 2014) and related capacities like emotional awareness, self-confidence, self-control, personal responsibility and adaptability, all of which are considered important goals in leader development programs (Day, 
2000).

Leadership educators are in a unique position to facilitate leadership learning by "engaging others in reflective practice and encouraging future leaders to look inward to clarify personal values as well as outward to understand how they connect to the larger whole" (Roberts, 2008, p. 118). A variety of pedagogical practices recommended to facilitate reflective practice are those such as case studies (Guthrie \& Jones, 2012), reflective discussions (Guthrie \& Jones, 2012), reflective journals (Jenkins, 2012), service-learning (Seemiller, 2006), and learning portfolios (Scott, 2010).

Portfolios have the potential to challenge and support students in developing their capacity to reflect upon their experiences. Research indicated that students who used portfolios achieved significantly higher reflection scores than other students (Scott, 2010). Although other factors also influenced the authors' decision to integrate the e-portfolio into the capstone experience, the vision has been to actualize the benefits of e-portfolios by challenging students to intentionally reflect on their entire graduate experience and provide a forum for students to "see the bigger picture and to understand holistically how they had learned through their graduate career" (Janosik \& Frank, 2013, p 18).

\section{Electronic Portfolio Assignment}

Students enrolled in this institution's graduate program in organizational leadership are required to participate in two capstone experiences. First, they must participate in an internship program or conduct an intensive research project. Second, they must develop a comprehensive electronic portfolio demonstrating proficiency for each of six broad learning outcomes of the program. The learning outcomes are:

Knowledgeable: Understand and apply the theoretical concepts of leadership, organizational behavior, and systems and evaluate their effectiveness in leading change initiatives.

Visionary and Change-Oriented: Demonstrate the ability to envision opportunities and desirable futures; develop means of attaining them and initiate change processes at individual, organizational and global levels.

Collaborative: Develop the capacity to foster successful teams and to create effective formal and informal collaborative networks.

Critical Thinking: Apply appropriate research and analysis techniques to investigate complex situations, to formulate informed decisions and to evaluate outcomes for individual and organizational improvement.

Global Competence: Demonstrate an understanding of the responsibility of organizations in society and develop the capacity to implement individual and organizational change to enhance society.

Communicative: Practice effective oral and written communication by conveying complex ideas and information in a coherent and professional manner, utilizing technology as appropriate.

Figure 1. Program Learning Outcomes 
The purpose of the e-portfolio requirement is to tap into the powerful benefits that challenge students to develop critical leader development capacities (e.g., self-awareness, selfregulation) and reflect on their personal and academic accomplishments and learning through their graduate careers. A secondary benefit is that the electronic portfolios can serve as an important indicator for internal program assessment activities.

While students primarily execute the e-portfolio project at the end of their program of study, they are encouraged to adapt a 'folio thinking' orientation (Barrett, 2003) early in their graduate program by being provided with the program's objectives and learning outcomes very early in their academic program. Faculty integrate the learning outcomes into their syllabi and course assignments, thereby providing an opportunity in each class to develop artifacts for the portfolios which demonstrate student proficiency among each of the program learning outcomes. Expectations are communicated early and reinforced often throughout their program. Students are also provided with resources for developing e-portfolios, links to example e-portfolios, and general tips and guidelines for choosing artifacts and completing electronic portfolios. Additionally, students are provided with a detailed rubric for assessing their electronic portfolio as well as example electronic portfolios from a variety of programs and disciplines.

Students are guided toward building an e-portfolio website using widely available web platforms such as Weebly, Wix, Digication, Google Sites, and Wordpress (or other similar sites). They are encouraged to construct their website and execute their e-portfolio in a way that makes sense to them and which encourages creativity, but also intentionally and specifically addresses the six broad learning outcomes of the program through critical reflection. They must choose artifacts related to each of the learning areas. For example, students may choose to include a comprehensive paper written for their qualitative research methods class as evidence of the outcomes "critical thinking" and "knowledgeable," whereas they may choose their "Personal Leadership Development" project to demonstrate "communication" and "vision and change oriented." They may choose group projects or service-learning projects they have completed to demonstrate "collaborative."

The e-portfolio must be more than simply a collection of artifacts and assignments from their classes, however. It must include intentional reflection about how and why the artifacts specifically demonstrate having met the learning outcomes. Additionally, since many of the students in this graduate program are professionally employed in a variety of organizations, they are also encouraged to include professional artifacts. For example, if a student has applied his or her learning to a specific professional project (i.e., creation of a leadership development training program, strategic planning for a department or organization, a recommendation report for change in organizational structure), it may also be incorporated into the e-portfolio.

\section{Analysis of Outcomes}

A detailed rubric was used to evaluate two completed e-portfolios from the Spring 2015 semester. Students were assessed on seven domains at one of four levels. The domains include: selection of artifacts; reflection/critique; use of multimedia; annotations; navigation; layout/readability; and quality of writing/mechanics. They are assessed as either novice (1), apprentice (2), proficient (3), or distinguished (4). Additionally, on the first two domains, 
selection of artifacts and reflection/critique, sub-scores are provided for each of the six learning outcomes.

It is early in the implementation phase of the new e-portfolio capstone experience at this institution. In fact, only two students have completed their portfolios to date, and ten are in the process of being completed by the end of the Fall 2015 semester. The purpose of this brief is to analyze the first e-portfolios that have been submitted, and reflect upon the process to-date in order to identify any problems in the process or execution related to e-portfolios.

While the sample size for the purposes of this early assessment of e-portfolios is too small to yield robust generalizable results, initial experiences applying the rubric to evaluate student e-portfolio performance has proven instructive. In the case of the first two e-portfolios submitted, the means across all domains were between 3.7 and 4.0, putting both in the "distinguished" category. Qualitative review of the portfolios and process has thus far been very positive and we are encouraged by the early results.

\section{Faculty Reflection}

As discussed earlier, there are two lenses through which one can view the use of eportfolios: to assess student learning (student-centered) or for assessment management purposes from a more administrative level (institution-centered). As we reflect on the process of implementing the e-portfolio, we must do so through both a student learning lens and an administrative lens.

Student Learning. Thus far, we are very pleased with the results from a student learning perspective. The quality of the completed e-portfolios exceeded our expectations. Both students turned in completely different styles of websites and chose different artifacts to demonstrate the learning outcomes, but articulated at a very sophisticated level how and why a particular artifact demonstrated deep learning. The level of intentional reflection and synthesis of leadership principles, practices, and behaviors was truly excellent.

One student chose to organize her portfolio around the six broad learning goals, while the other took us on a chronological journey of his graduate career, organizing it semester-bysemester, incorporating several job changes along the way. The students were empowered through the process to create a site that was reflective of both who they are and what they had learned. We encouraged them to create their own voice rather than prescribing a strict format or template. Both websites were indeed very reflective of the personalities and styles of their authors. Thus, one was more "academic" in nature, and one far more personal, including journal entries and personal pictures in addition to papers and projects he had completed during his graduate experience. We certainly plan to continue to encourage creativity, individual voice, and autonomy in the process in the future, based on these early results. Ultimately, students thus far have risen to the occasion and performed admirably in demonstrating their learning through their graduate experience. Our decision to not provide a prescribed platform, format or template turned out to be a good one, based on these early results. 
Administration. Despite the resounding success from a "student learning" lens, administering the e-portfolio project was not without several challenges. As previously stated, only two students have completed the e-portfolio project; however, ten more students are presently at the final stages of their graduate project and are intensively working toward completion, while dozens more are at various other stages in their graduate experience within our program. At times students sought clarification and guidance regarding both content and design and other logistics. Student inquiries often reflected either confusion or a general misunderstanding regarding the e-portfolio project or request for additional assistance due to technology related issues. For instance, recently one student's computer hard drive 'crashed,' causing her to lose all of her graduate assignments and course activities from previous semesters. Since the Content Management System (CMS) used by our university automatically moves previous semester courses to 'inactive' status and therefore are no longer available to students, this student's challenge in securing prior graduate work was quite significant. Additionally, several students expressed a desire to examine exemplars that model the expectations for the eportfolio project. As this initiative is new for our program, we provided them with examples of student e-portfolios from graduate programs of other universities. As we continue to have graduates complete e-portfolios from our program, we will have more exemplars to provide, but will likely still continue to not prescribe a specific platform or format.

Additionally, informal feedback from students indicates that planning and executing the e-portfolio project requires a significant amount of time and mental energy. At present, there is only a single due date that students are to have completed the e-portfolio by which it is then reviewed by departmental faculty. The e-portfolio, along with the corresponding final documentation of their capstone projects (either a major research paper or an internship report), requires an extraordinary effort the final weeks of the semester. Students can benefit from a more structured timeline by which to have benchmarks to aid them in more effective pacing of the project throughout their final semester.

\section{Student Reflection}

As stated, portfolios have become a popular alternative to comprehensive exams in many graduate programs across the nation and the world. With the world's ever-evolving technology, it is no surprise that e-portfolios have manifested in graduate education. This is largely due to the active and experiential nature of designing, collecting artifacts, and reflecting on learning throughout the portfolio process. My graduate e-portfolio served as an opportunity for me to showcase what I learned, how I learned it, and how I will use the information in my future; it was intended to describe learning from my own personal perspective. More importantly, the portfolio process helped me answer the posed question in leadership education, "So what?" The answer to this question lies deep in the design and organization of my e-portfolio.

Choosing a platform for my e-portfolio was somewhat difficult. I had no experience in website design, so I wanted to use a service that was simple to use; therefore, I chose Weebly. This platform offered a variety of templated website designs, and my responsibility was to fill in the fields with content. Organizing my e-portfolio was largely influenced by my background in learning outcomes planning and assessment. Working in higher education for several years, this style of thinking had become my norm, and it was natural to start with the program's learning 
outcomes and build my portfolio around them. I built the site as if I was compiling an annual assessment report.

In many of the essays, which were accompanied by course assignments and experiences, is the ability to reflect on what I learned and how it will assist me in future endeavors. I am without doubt that while creating my e-portfolio, I was challenged to delve deeper into my learning experiences, and justify why I endured two years of advanced study in organizational leadership. Not only did I confirm my own knowledge through this reflection period, I also affirmed the graduate program's learning goals during the process. Moreover, the development and reflective process of the e-portfolio was an opportunity for me to more clearly define how my knowledge of the subject was applicable to my current and future work, which is largely demonstrated in the artifacts supporting my learning. In addition, reflecting on my culminating experience was the most enriching process as it tied directly to program development - a large portion of my current position. Overall, the project confirmed to both myself and my professors that my graduate education meant something, and was worth it.

As a result of participating in the e-portfolio experience, I am much more able to discuss what I learned in my graduate program with colleagues and potential employers because I actively contributed to my learning process, which is something I would be unable to do by simply echoing learned scholarly information by means of comprehensive exams.

\section{Recommendations and Conclusion}

Based on the faculty and student experiences regarding the e-portfolio project we offer several recommendations for future use. First, we recommend building a more formalized structure along with corresponding target due dates for deliverables of the e-portfolioproject throughout the capstone experience. This recommendation may yield several important advantages. For instance, students would be able to more effectively disperse the time and energy more evenly throughout the semester. This may also provide opportunities for students to evaluate other students' e-portfolios and offer feedback to each other, and gain valuable insight to improve their personal e-portfolios (Ring \& Ramirez, 2012).

Additionally, the high scores achieved on all dimensions of the rubric used toevaluate student e-portfolios suggest the need to reevaluate the definitions for performance levels on each learning outcome. This may not have been an anomaly, given that the two students who have completed the e-portfolio all performed exceptionally well in other graduate coursework. Still, further refinement of the grading rubric may be warranted before using the rubric scores for program and institutional level assessment.

Finally, we recommend communicating early, and often, with students regarding the expectation of the e-portfolio requirement during their capstone project. We are now intentionally sharing with students the general expectation of the e-portfolio project along with the corresponding guidelines during their initial advising appointments. This information will hopefully encourage students to more effectively understand expectations, but also urge them to maintain electronic documentation of their coursework on multiple data-storage devices. 
Moreover, we are currently contemplating means by which we can encourage students to create and maintain their e-portfolios much earlier in the program than just their final semester. For instance, having students submit an initial draft of the e-portfolio at the midpoint of their graduate program can afford us the opportunity to provide faculty and/or peer feedback, which has the potential of being a powerful formative assessment tool, rather than simply at the end of the program as a summative assessment technique (Ring \& Ramirez, 2012).

Granted, given the small sample thus far, we cannot state definitively that the e-portfolio is an unqualified success. Nonetheless, initial results of the e-portfolio are very promising. We encourage other scholars and practitioners to further develop and refine research-based best practices for e-portfolios that seek to strike a balance between e-portfolios for learning and assessment management systems. We are delighted to share our materials with others interested in e-portfolios.

\section{References}

Abrami, P.C., \& Barrett, H.C. (2005). Directions for research and development of electronic portfolios. Canadian Journal of Learning and Technology, 31(3). Retrieved from http://www.cjlt.ca/index.php/cjlt/article/view/92/86

Allen, S.J., \& Hartman, N.S. (2008). Sources of learning in student leadership development programing. Journal of Leadership Studies, 3(3), 6-16. doi:10.1002/jls.20119

Barrett, H. (2003). Electronic portfolios. In A. Kovalchick \& K. Dawson (Eds), Educational technology: An encyclopedia. Santa Barbara, CA: ABC-CLTO.

Barrett, H. (2004). Differentiating Electronic Portfolios and Online Assessment Management Systems. In Society for Information Technology \& Teacher Education International Conference (Vol. 2004, No. 1, pp.46-50).

Barrett, H. C. (2007). Researching electronic portfolios and learner engagement: The REFLECT initiative. Journal of adolescent \& adult literacy, 50(6), 436-449.

doi:10.1598/JAAL.50.6.2

Bhattacharya, M., \& Hartnett, M. (2007, October). E-portfolio assessment in higher education. In Frontiers In Education Conference-Global Engineering: Knowledge Without Borders, Opportunities Without Passports, 2007. FIE'07. 37th Annual (pp. T1G-19). IEEE.

Chau, J. (2007). A Developer's Challenges on an e-portfolio Journey. Proceedings Ascilite Singapore, 2007.

Daudlin, M.W., (1996). Learning from experience through reflection. Organizational Dynamics, 24(3), 36-48. doi:10.1016/S0090-2616(96)90004-2 
Day, D.V. (2000). Leadership development: A review in context. The Leadership Quarterly, 11(4), 581-613. doi:10.1016/S1048-9843(00)00061-8

Day, D.V., Fleenor, J.W., Atwater, L.E., Sturm, R.E., \& McKee, R.A. (2014). Advances in leader and leadership development: A review of 25 years of research and theory. The Leadership Quarterly, 25(1), 63-82. doi:10.1016/j.leaqua.2013.11.004

Dewey, J. (1933). How we think: A restatement of the relation of reflective thinking to the educative process. Boston: D. C. Heath.

Elbow, P., \& Belanoff, P. (1986). Portfolios as a substitute for proficiency examinations. College Composition and Communication, 37, 336-339.

European Institute for E-Learning EIfEL. (2009). ePortfolio: A European perspective. Retrieved January 26, 2015 from http://www.adameurope.eu/prj/4888/prd/31/1/ePortfolio\%20a\%20European\%20Perspective\%5B1\%5D.pdf

Guthrie, K.L., \& Jones, T.B., (2012). Teaching and learning: Using experiential learning and reflection for leadership education. New Directions For Student Services, 140, 53-63. doi: $10.1002 /$ ss.20031

International Leadership Association. (2009). Guiding questions: Guidelines for leadership education programs.

Janosik, S.M., \& Frank, T.E. (2013). Using eportfolios to measure student learning in a graduate preparation program in higher education. International Journal of ePortfolio, 3(1), 13-20.

Jenkins, D.M. (2012). Exploring signature pedagogies in undergraduate leadership education. Journal of Leadership Education, 11(1), 1-27.

Kolb, D.A. (1984). Experiential learning: Experience as the source of learning and development. Upper Saddle River, N.J.: Prentice Hall.

Lorenzo, G., \& Ittelson, J. (2005). An overview of e-portfolios. Educause Learning Initiative, 1, $1-27$.

Lyons, N. (1998). Portfolios and their consequences: Developing as a reflective practitioner. In N. Lyons (Ed.), With portfolio in hand: Validating the new teacher professionalism (pp. 247-264.) New York, NY: Teachers College Press.

McCall, M.W., Jr. (2004). Leadership development through experience. Academy of Management Executive, 18(3), 127-130. doi:10.5465/AME.2004.14776183

Mezirow, J. (1998). On critical reflection. Adult Education Quarterly, 48(3), 185-199. doi: 10.1177/074171369804800305 
Reese, M., \& Levy, R. (2009). Assessing the future: E-portfolio trends, uses, and options in higher education. Research Bulletin, 4, 1-12.

Riggio, R. E., Ciulla, J., \& Sorenson, G. (2003). Leadership education at the undergraduate level: A liberal arts approach to leadership development. The future of leadership development, 223-236.

Ring, G., \& Ramirez, B. (2012). Implementing eportfolios for the assessment of general education competencies. International Journal of ePortfolio, 2(1), 87-97.

Roberts, C. (2008). Developing future leaders: The role of reflection in the classroom. Journal of Leadership Education, 7(1), 116-130.

Scott, S.G. (2010). Enhancing reflection skills through learning portfolios: An empirical test. Journal of Management Education, 34(3), 430-457. doi: 10.1177/1052562909351144

Seemiller, C. (2006). Impacting social change through service learning in an introductory leadership course. Journal of Leadership Education, 5(2), 41-49.

Shulman, L.S. (2005). Signature pedagogies in the disciplines. Daedalus, 134(3), 52-59.

\section{Author Biographies}

Dr. Brent J. Goertzen is a Professor of Leadership Studies at Fort Hays State University and director Department of Leadership Studies' graduate program. He has fifteen years of experience teaching coursework in the field of leadership. His expertise is in the areas of leadership theory, leadership in team contexts, fieldwork in leadership and research methods. Brent has research interests in the areas such as assessment of leadership education, pedagogical practices of leadership education, and group dynamics.

Dr. Jeni McRay is an Assistant Professor of Leadership Studies at Fort Hays State University and teaches undergraduate courses in the international cross-border program as well as virtual graduate courses. She has seventeen years of experience teaching and training adult learners and professionals, including nine years of teaching online graduate-level courses in leadership and education. Areas of expertise include leadership development training, faculty development, higher education administration, and online instructional design and pedagogy.

Kaley Klaus is a Lecturer of Leadership Studies and the Director of the Voss Advanced Leadership Undergraduate Experience (VALUE) at Fort Hays State University. Her areas of expertise include leadership theory, program development, and program assessment and evaluation. Kaley completed a BA in Communication Studies in 2012, and earned her MPS in Organizational Leadership in 2015, from Fort Hays State University. 